\title{
Miscellany
}

\section{Prison Personal Empowerment Programme}

Many of the 500 inmates of Holloway Women's Prison are there because of drug-related crimes. The Personal Empowerment Programme (PEP) offers these women the opportunity to stop using chemicals completely. Started in 1993, with a $£ 9,000$ grant from the King's Fund, PEP offers support and help through psychotherapy, drama therapy and lectures to groups of eight women between the ages of 18 and 40 . The drug users must show a commitment to coming off drugs by themselves. PEP's underlying principle is that users must deal with their drug addiction before their other problems can be dealt with.

\section{Quality assurance network for mental health}

Q-Net, the Mental Health Quality Assurance Network, is a new initiative by The Sainsbury Centre for Mental Health. Any agency, group or individual with an interest in quality assurance in mental health can join Q-Net. Members do not have to be using any particular QA system. Anyone interested in joining Q-Net should contact Alison Hooper, Development Officer, The QA Project, The Sainsbury Centre for Mental Health, 134-138 Borough High Street, London SE1 1LB (telephone 0171403 8790; fax 0171403 9482).

\section{New Defeat Depression educational package}

A new educational package Depression in the Workplace has been produced with the aim of encouraging employers to consider this important issue seriously. Copies of the pack are available for $\$ 20.00$ from the Defeat Depression Campaign, 17 Belgrave Square, London SWIX 8PG; cheques to be made payable to The Royal College of Psychiatrists (Defeat Depression Campaign)'. To complement this package, the Defeat Depression Campaign has produced a help is at hand leaflet Depression in the Workplace and a poster. The leaflet looks at what depression is, the effects of depression at work and what can be done. The leaflet costs 40 p (orders $100+$ at $25 p$ per leaflet); the poster costs 25p. Both are available from the Defeat Depression Campaign, 17 Belgrave Square, London SW IX 8PG.

\section{New publications}

Partners in Change: care planning in mental health services by Rose Echlin (price £8.95) is based on project work in Clwyd, Leeds and Swindon in 1992-3 and shows how service users and professionals can work together in the care planning process. Tackling Inequalities in Health: an agenda for action (price £14.95) shows how much avoidable death, disease and disability could be significantly reduced. Both publications are available from BEBC, PO Box 1496. Parkstone, Poole, Dorset BH12 3YD (telephone 0800 262260) and are also available from the King's Fund Centre bookshop.

The Mental Health Foundation has published an information sheet Severe Mental Illness: the problem of resources. For further information about this and other Mental Health Foundation publications, please contact The Information Officer, 37 Mortimer Street, London WIN 8JU (telephone 0171580 0145).

Two booklets Making Sense of Drugs and Treatments: Minor Tranquillizers (price £2.20) and How to Survive Family Life in the 90s (price 50p plus a 29p SAE) are available from MIND Publications, 15-19 Broadway. Stratford, London E15 4BQ.

Journal of Clinical Geropsychology is a new quarterly journal which publishes theoretical, review and clinical papers on the assessment, diagnosis, categorisation, prevention, and treatment of psychological problems in older adults. All manuscripts, editorial queries, and comments should be addressed to Michel Hersen, PhD, or Vincent B. Van Hasselt, $\mathrm{PhD}$, Center for Psychological Studies, Nova Southeastern University, 3301 College Avenue, Fort Lauderdale, FL 33314, USA. Subscription information is available from the Advertising Manager, Plenum Publishing Corporation, 233 Spring Street, New York NY 10013-1578, USA. 